\title{
PENDAMPINGAN PENGELOLAAN RUMPIN DI RW 11 TAMBAKAJI KECAMATAN NGALIYAN KOTA SEMARANG
}

\author{
Mudzanatun*, Muhamad Arif budiman, Ismatul Khasanah , Heri Saptadi, \\ Fine Reffiane \\ Universitas PGRI semarang, Indonesia \\ *mudzanatun@gmail.com
}

\begin{abstract}
RUMPIN (Rumah Pintar) is a non-profit business to assist children in getting free learning. Children who participate in the RUMPIN program are stimulated to learn while playing oriented to the interests and talents of theirs so that children become more comfortable in RUMPIN, and without realizing, in addition to increasing knowledge, children also avoid negative activities. There is no RUMPIN in RW 11 Tambakaji, Ngaliyan District, Semarang City. The Community Service Team wants to provide a solution to this problem by helping establish RUMPIN at RW 11 Tambakaji, Ngaliyan District, Semarang City. The methods used are socialitation, mentoring, training, and workshops. The socialization method was used to introduce RUMPIN to all residents of RW 11 Tambakaji, Ngaliyan District, Semarang City. The mentoring method is used to help residents of RW 11 Tambakaji, Ngaliyan District, Semarang City form the RUMPIN management and program. Training and workshop methods are used to help residents create tentors who will work at RUMPIN. From this community service program, the service team found that residents were enthusiastic about the existence of RUMPIN, and they also stated their availability in order to help forming the RUMPIN, become active officials, participate actively in creating work programs, and actively participate in being a tentor. The conclusion of this community service program is that residents of RW 11 Tambakaji, Ngaliyan District, Semarang City are aware of the importance of RUMPIN in their neighborhoods because it can help their children to gain more knowledge besides the knowledge they get in formal education.
\end{abstract}

Keywords: RUMPIN, socialitation, program, management, tentor

Abstrak

RUMPIN (Rumah Pintar) merupakan usaha non profit untuk membantu anak dalam mendapatkan pembelajaran secara gratis. Anak-anak yang mengikuti program RUMPIN distimulasi untuk belajar sambil bermain dengan berorientasi pada minat dan bakat yang dimiliki anak sehingga anak menjadi lebih betah berada di Rumpin, dan tanpa sadar, selain pengetahuan bertambah, anak juga terhindar dari kegiatan negative. Di RW 11 Tambakaji Kecamatan Ngaliyan Kota Semarang belum terdapat RUMPIN. Tim Pengabdi ingin memberikan solusi untuk masalah ini dengan membantu mendirikan RUMPIN di RW 11 Tambakaji Kecamatan Ngaliyan Kota Semarang. Metode yang digunakan adalah sosialisasi, pendampingan, pelatihan, dan workshop. Metode sosialisasi digunakan untuk mengenalkan RUMPIN kepada seluruh warga RW 11 Tambakaji Kecamatan Ngaliyan Kota Semarang. Metode pendampingan digunakan untuk membantu warga RW 11 Tambakaji Kecamatan Ngaliyan Kota Semarang membentuk pengurus dan program RUMPIN. Metode pelatihan dan workshop digunakan untuk membantu warga menciptakan tentor yang akan bekerja di RUMPIN. Dari program pengabdian kepada masyarakat ini tim pengabdi menemukan bahwa warga antuasias dengan keberadaan RUMPIN, dan mereka juga menyatakan ketersediaannya dalam rangka ikut membantu pembentukan RUMPIN, ikut aktif menjadi pengurus, ikut aktif menciptakan program-program kerja, dan ikut aktif menjadi tentor. Kesimpulan dari kegiatan program pengabdian kepada masyarakat ini adalah bahwa warga RW 11 Tambakaji Kecamatan Ngaliyan Kota Semarang sadar tentang pentingnya keberadaan RUMPIN di lingkungan mereka karena hal tersebut bisa membantu anak-anak mereka untuk memperoleh lebih banyak pengetahuan selain pengetahuan yang mereka dapatkan di bangku pendidikan formal.

Kata kunci: RUMPIN, sosialisasi, program, pengurus, tentor

Submitted: 2020-06-11

Revised: 2020-10-19

Accepted: 2020-10-26 


\section{Pendahuluan}

Tambakaji sebagai bagian wilayah kecamatan Ngaliyan. Pada Bulan November 2018 kecamatan memotivasi wilayahnya dengan mengadakan lomba posyandu terintegrasi. Wilayah kelurahan ditunjuk untuk maju mewakili kelurahan Tambakaji. Kondisi posyandu terintegrasi dengan pos PAUD. Kegiatan ini telah dilaksanakan sejak awal tahun acaran baru yaitu bulan Juli. Warga dipersiapkan oleh para kader posyandu dan para ibu rt 1-5 untuk menimbangkan balitanya ke posyandu. Jumlah balita di wilayah RW XI ada 75 terbagi menjadi dua tempat yaitu posyandu Cempaka 1 dan Cempaka 2. Pos yandu cempaka 2 tergabung dengan pos Paud Cendekia Mandiri. Maka kegiatan penimbangan balita di posyandu cempaka bergabung dengan pospaud. Penimbangan semula di ruang pansimas pindah ke ruang kelas POS PAUD Cendekia Mandiri. Hal ini berlangsung sejak bulan Juli 2018. Dengan adanya penambahan personal pengunjung dipos paud maka pos Paud mengeluarkan mainan dan buku bacaan yang dimiliki. Ibu pengantar penimbangan sambil menunggu penimbangan mendapat tambahan ilmu mengenai tumbuh kembanganak oleh pengurus kelompok bina balita RW XI, Ibu Ika. Kegiatan ini disaksikan oleh petugas kelurahan yang telah ikut serta membimbing dari POKJA 2, Ibu dyah. Maka dengan berkembangkan posyandu diusulkanlah kegiatan rumah pintar (Rumpin ) di RW XI. Mulailah bulan November 2018 terbentuk Rumpin di RW XI. Rumpin terintegrasi dengan posyandu dan pos Paud Cendekia mandiri.

Namun pelaksanaan rumpin belum maksimal. Warga masyarakat RW XI belum tahu persis apa itu Rumpin, Pihak pengurus PKK juga belum mengerti apa lagi program kerja Rumpin. Hal ini terjadi karena pembentukan Rumpin tidak dimulai dari kebutuhan warga namun kepentingan kelurahan Tambakaji yang akan maju lomba kegiatan PKK kelurahan tingkat kecamatan. Hal ini mengakibatkan yang mengerti apa itu rumpin hanya pengelola pos paud sj. Karena pos paud terintegrasi dengan rumpin dan posyandu. Dengan kondisi demikian menjadikan PKK RW belum memahami kedudukan Posyandu, BKB, Rumpin, dan Pos PAUD. Oleh karena itu pendampingan Rumpin kali ini tim pengabdi akan mensosialisasikan semua kegiatan ini pada rapat PKK RW. Selanjutnya akan minta dukungan kepada kelurahan untuk selalu mendapatkan pembinaan setiap bulan. Wujud kerja yang dapat diukur program pengabdian ini yaitu meminta bantuan tim PKK Kelurahan yang diketuai Bu Lurah Tambakaji untuk menjelaskan pensosialisasikan kepada PKK RW tentang Rumpin, BKB, Posyandu, dan Pos PAUD. Tujuan sosialisasi ini untuk menyadarkan pengurus PKK RW ikut handar beni dan ikut serta mendukung program kerja rumpin posyandu dan pospaud. Bahasa Inggris untuk anak SD dengan bermain dan membaca berbahasa Inggris anak SD.

Dengan kondisi mitra yang demikian pentingnya penanganan RumPin di RW 11 maka tim pengabdi terpanggil untuk membantu mitra melakukan pengabdian tentang penjelasan tentang Rumpin BKB Pos PAUD dan Posyandu di RW 11. Focus pegram pengabdian pada RumPin mengenai pendampingan remaja RW 11 menjadi tentor belajar Bahasa Inggris siswa SD. 


\section{Metode}

Berdasarkan solusi pada pembahasan dan target luaran yang ingin dicapai maka metode yang ditawarkan dalam kegiatan pengabdian kepada Rumah Pintar di RW 11 Kelurahan Tambakaji Kecamatan Ngaliyan Kota Semarang adalah pelatihan dan pendampingan. Metode pelaksanaan pengabdian ini dilakukan dalam beberapa bentuk yaitu pelatihan, workshop dan pendampingan pada Rumah Pintar di RW 11 Kelurahan Tambakaji Kecamatan Ngaliyan Kota Semarang melalui tiga tahapan.

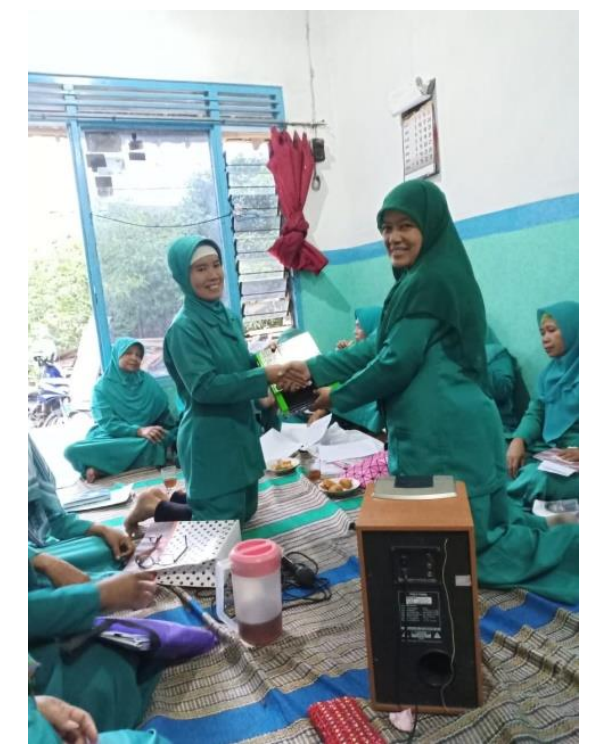

Gambar 1. Sosialisasi keberadaan RUMPIN

Pada tahap pertama tim pengabdi memberi beberapa jenis pendampingan terkait sosialisasi keberadaan Rumah Pintar di RW 11 Kelurahan Tambakaji Kecamatan Ngaliyan Kota Semarang dan pembentukan pengurus Rumah Pintar di RW 11 Kelurahan Tambakaji Kecamatan Ngaliyan Kota Semarang. Pada tahap kedua tim pengabdi memberi beberapa jenis pelatihan terkait pmbentukan program yang terdiri atas SENTRA BACA, SENTRA BERMAIN, SENTRA KRIA, SENTRA PANGGUNG, dan SENTRA AUDIO VISUAL serta pelatihan untuk tentor-tentor Rumah Pintar di RW 11 Kelurahan Tambakaji Kecamatan Ngaliyan Kota Semarang. Pada tahap ketiga diadakan advokasi atau pendampingan pengelolaan Rumah Pintar secara berkala. Tim PKM mendampingi pengurus Rumah Pintar untuk melengkapi administrasi dan kelengkapan dokumen seperti: Buku inventaris, buku pengunjung, dan kelengkapan administrasi lainnya.

\section{Hasil Dan Pembahasan}

Pendidikan merupakan sebuah hal penting yang harus didapatkan oleh masyarakat terutama anak. Pembekalan terhadap pendidikan seyogyanya menjadi hal yang utama dan wajib didapatkan oleh anak untuk menjadi bekal masa depan. Dalam peraturan pemerintah sendiri sudah mencanangkan wajib belajar 12 tahun bagi setiap warga negara Indonesia. Pendidikan itu sendiri sebenarnya tidak hanya didapatkan di dalam kelas. Kegiatan-kegiatan pendidikan non formal menjadi salah satu cara untuk menambah, mengganti dan melengkapi setiap individu dalam mendapatkan haknya di bidang 
pendidikan.

Masyarakat gemar belajar dapat terwujud apabila setiap warga masyarakat selalu mencari dan menemukan sesuatu yang baru dan bermakna, meningkatkan kemampuan, dan mengembangkan dan melalui kegiatan belajar. Kegiatan belajar telah menjadi kebutuhan hidup dan kebiasaan masyarakat. Kegiatan belajar yang dilakukan oleh setiap warga masyarakat tidak terbatas hanya untuk mengetahui atau belajar sesuatu (learning how to learn), tidak pula belajar hanya untuk, memecahkan masalah yang timbul dalam kehidupan (learning how to solve problems). Kegiatan belajar yang mereka lakukan terarah untuk kepentingan dan kemajuan kehidupannya (learning how to be), belajar untuk melakukan sesuatu (learning how to do), dan belajar untuk hidup bersama (learning how to live together). Masyarakat gemar belajar akan sekaligus menjadi prasyarat bagi tumbuhnyamasyarakat terdidik (educated society).

Satuan pendidikan Nonformal seperti PKBM, sanggar belajar, pondok pesantren, padepokan, dan penyelenggara kegiatan pendidikan lainnya seperti Rumah Pintar dan lain sebagainya mempunyai kapasitas dalam pengembangan pendidikan nonformal yang merupakan bagian penting dari program pembangunan pendidikan dan pembangunan masyarakat secara keseluruhan. Pendidikan nonformal merupakan usaha sadar yang disengaja untuk membantu masyarakat agar mereka dapat mengubah sikap dan prilaku membangun serta dapat menggunakan sikap dan prilaku tersebut dalam meningkatkan taraf hidupnya.

Program-program Pendidikan Luar Sekolah tentu menjadi sebuah wadah atau lembaga pendidikan yang dibentuk dan dikelola dari, oleh dan untuk masyarakat yang secara khusus berkonsentrasi dalam upaya pembelajaran dan pemberdayaan masyarakat sesuai dengan kebutuhan.

Berdasarkan prioritas permasalahan yang telah disepakati bersama mitra meliputi pendampingan pengelolaan Rumpin Di RW 11 Tambakaji Kecamatan Ngaliyan Kota Semarang, memberikan motivasi pentingnya pengelolaan Rumah Pintar yang terintegrasi dengan kebiasaan membaca dan pelestarian budaya. Justifikasi pengusul bersama mitra dalam menentukan persoalan prioritas yang disepakati untuk diselesaikan selama pelaksanaan Program Kemitraan Masyarakat (PKM) yaitu pengusul Program Kemitraan Masyarakat (PKM) bersama mitra mencari solusi dari permasalahan yang ada terutama permasalahan yang bersifat spesifik, konkrit serta benar-benar merupakan permasalahan prioritas mitra.

Metode pendekatan yang ditawarkan untuk menyelesaikan persoalan mitra program yang telah disepakati bersama untuk kurun waktu realisasi Program Kemitraan Masyarakat (PKM) adalah sebagai berikut: (1) Sosialisasi pengelolaan rumah pintar di enam rapat RT tanggal 3 Nov 2019-30 Nov 2019 dan rapat PKK RW tanggal 21 Desember 2019 (2) Tanggal 18 Januari 2020 pendampingan administrasi Rumah pintar Pendampingan membentuk wadah belajar bagi anak-anak dan juga masyarakat. (3) Menumbuhkan kesadaran masyarakat untuk peduli akan kebutuhan membaca bagi masyarakat sekitar, pelaksanaan centra baca terdapat di pojok baca masjid Baitul Muttaqin untuk warga RT 01dan 02, pojok baca di TPQ Muhajirin utuk RT 04, pojok baca untukwarga RT 03 dan 05 di mushola Baitul Abidin, sdangkan kelompok keluarga PAUD ada di Pos PAUD Cendekia Mandiri. (4) Meningkatkan kualitas SDM serta Mendukung pembangunan manusia seutuhnya 


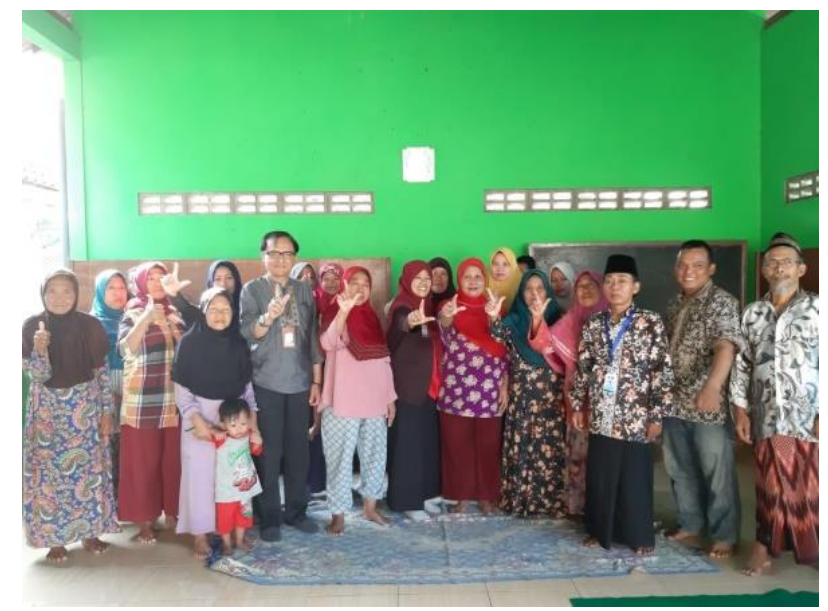

Gambar 2. Pembentukan pengurus RUMPIN

Program yang diselenggarakan oleh RUMAH PINTAR di RW 11 Tambak Aji Kecamatan Ngaliyan, Semarang diusulkan ada lima: Sentra Baca, Sentra Bermain, Sentra Kria, Sentra Panggung, Sentra Audio Visual.

1. Sentra Baca

Sentra baca adalah sebuah lembaga yang menyediakan bahan bacaan yang dibutuhkan oleh masyarakat sebagai tempat penyelenggaraan pembinaan kemampuan membaca dan belajar, sekaligus sebagai tempat untuk mendapatkan informasi bagi masyarakat. Pengelola sentra baca adalah mereka yang memiliki dedikasi dan kemampuan teknis dalam mengelola dan melaksanakan layanan kepustakaan kepada masyarakat. Bahan pustaka adalah semua jenis bacaan dalam berbagai bentuk media. Pengadaan program sentra baca Rumah Pintar TambakAji Ngaliyan ini bertujuan untuk meningkatkan minat membaca bagi masyarakat. Oleh karena itu keberadaan sentra baca sangat penting sebagai sarana belajar masyarakat. Untuk itu kemampuan, ketrampilan, dan kinerja pengelola harus ditingkatkan sehingga dapat mengelola sentra baca sebagai mana mestinya. Tujuan program sentra baca Rumah Pintar Tambak Aji Ngaliyan untuk memberikan pelayanan Taman Bacaan Masyarakat adalah (a) Membangkitkan dan meningkatkan minat membaca masyarakat sehingga terciptanya masyarakat yang cerdas, (b) Menjadi sebuah wadah kegiatan belajar masyarakat, (c) Menyediakan bahan bacaan untuk masyarakat sekitar. 


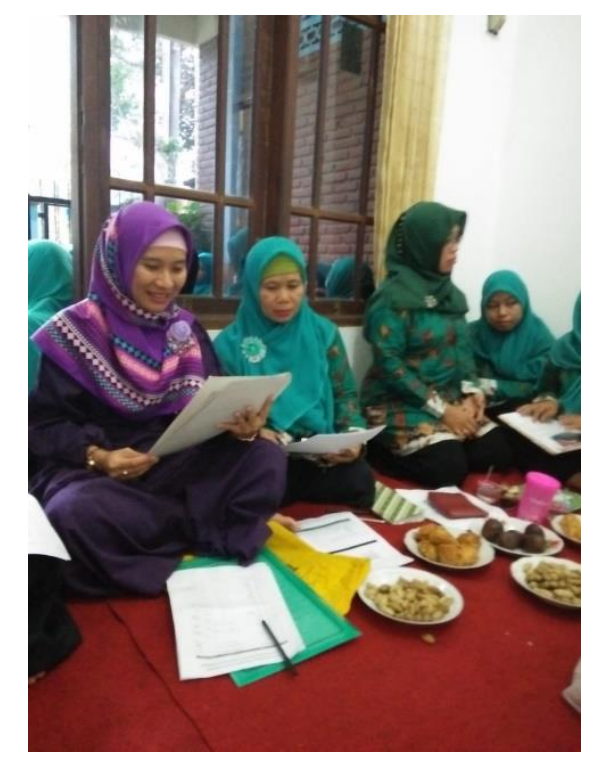

Gambar 3. Pendampingan pembentukan program RUMPIN

2. Sentra Bermain

Sentra bermain adalah layanan yang memungkinkan pengunjung RUMPIN untuk mampu memainkan berbagai permainan yang ada dan ditawarkan oleh pihak pengelola RUMPIN. Materi untuk sentra bermain di Rumpin Di RW 11 Tambakaji Kecamatan Ngaliyan Kota Semarang adalah berbagai macam permainan tradisional, misalnya: dakon, engklek, gobak sodor, dan lain sebagainya. Hal ini bertujuan untuk melestarikan kearifan local serta mengenalkan kembali beberapa permainan tradisional yang hamper punah.

3. Sentra Kria

Sentra kria merupakan layanan yang disediakan Rumpin Di RW 11 Tambakaji Kecamatan Ngaliyan Kota Semarang bagi para pengunjung yang memfokuskan pada berbagai hal yang menyangkut dengan ketrampilan tangan. Sebagai missal adalah membuat berbagai hasil karya kerajinan dari berbagai jenis limbah yang ada di sekitar lingkungan Rumpin Di RW 11 Tambakaji Kecamatan Ngaliyan Kota Semarang, misalnya limbah plastic, limbah kertas, limbah kayu, dan lain sebagainya.

4. Sentra Panggung

Sentra panggung merupakan layanan yang ada di Rumpin Di RW 11 Tambakaji Kecamatan Ngaliyan Kota Semarang untuk melatih anak-anak bermain peran. Hal ini memiliki berbagai aspek positif, salah satunya adalah melatih anak untuk berani tampil di depan umum.

5. Sentra audio visual

Sentra audio visual adalah layanan yang ada di Rumpin Di RW 11 Tambakaji Kecamatan Ngaliyan Kota Semarang yang memfokuskan pada ketrampilan untuk mengoperasikan computer. Terdapat berbagai macam aplikasi yang ada di computer, salah duanya adalah voice recorder (perekam suara, dan video recorder (perekam video). Sentra audio visual merupakan layanan yang akan melatih anakanak yang ada di Rumpin Di RW 11 Tambakaji Kecamatan Ngaliyan Kota Semarang untuk terampil dalam dua hal itu. Produk luaran yang diharapkan dari sentra ini adalah bahwa nantinya naak-anak yang ada di Rumpin Di RW 11 
Tambakaji Kecamatan Ngaliyan Kota Semarang mampu membuat video dengan berbagai macam tema yang nantinya akan mereka upload ke media social youtube untuk menyebarluaskan informasi mengenai keberadaan Rumpin Di RW 11 Tambakaji Kecamatan Ngaliyan Kota Semarang kepada masyarakat luas yang aktif di dunia maya. Hal ini sejalan dengan perkembangan zaman dimana pada era sekarang ini masyarakat lebih aktif di dunia maya daripada di dunia nyata.

\section{Kesimpulan}

Kesimpulan dari kegiatan Program Kemitraan Masyarakat (PKM) dalam pendampingan Rumah Pintar RW 11 Tambak Aji Ngaliyan, Semarang dengan mitra adalah bahwa pelaksaan berjalan dengan sukses dan apa yang direncanakan tercapai sesuai target, yaitu: (1) Membentuk wadah belajar bagi anak-anak dan juga masyarakat yang berwujud Rumah Pintar (2) Menumbuhkan kesadaran masyarakat untuk peduli akan kebutuhan membaca bagi masyarakat sekitar dengan sosialisasi keberadaan RUMPIN kedapa masyarakat di RW 11 Tambak Aji Ngaliyan, Semarang (3) Meningkatkan kualitas SDM serta Mendukung pembangunan manusia seutuhnya dengan berbagai macam pelatihan (pelatihan bagi pengurus RUMPIN, pelatihan pembentukan program RUMPIN, pelatihan bagi tentor). Saran yang ingin disampaikan pengabdi kepada masyarakat luas adalah perlunya pendampingan pemerintah kota dan jajarannya secara terus menerus agar dapat meminimalkan kekeliruan fungsi Rumah Pintar yang ada; Masyarakat sekitar, remaja serta anak-anak agar senantiasa memanfaatkan keberadaan Rumah Pintar dengan sebagaimana mestinya.

\section{Daftar Pustaka}

Amik, Fajjin. Saefurohman, Usep. 2018. Menuju Guru dan Siswa Cerdas. Bandung: LeutikaPrio

Crary, Elizabeth. 2013. Children's Problem Solving: Aku Ingin Bermain. Jakarta: Kanisius

Christina. 2019. Mengajar Membaca Itu Mudah. Bandung: Alaf Media

Erlangga. 2017. Perilaku dan Manajemen Organisasi. Jakarta: Erlangga

Hanindita, Meta. 2017. Play and Learn (Mendampingi Anak usia 0-4 tahun belajar sambil bermain). Jakarta: Stiletto Book.

Murtie, Afin. 2013. Mengajari Anak Calistung dengan Bermain. Jakarta: Gramedia Pustaka Utama

Pujiati, Maya. 2017. Cara Mudah Mengajar Anak Membaca: Mengajari Anak Membaca Menjadi Ringan dan Menyenangkan. Surabaya: Nauka Publishing

Suryono, Yoyon. 2012. Buku Rumah Pintar. Yogyakarta: UNY Press

Sandora, Lisna. 2004. Pembinaan Anak Jalanan Melalui Rumah Singgah di Sumatera barat: laporan penelitian. Padang: Balitbang Provinsi Sumatera Barat 